\title{
Effect Of Degree Binary Complex Of Imprint Ion On The Extraction Of Zircon Ion
}

\author{
Aladin Sianipar ${ }^{1}$, Amran M.B $^{2}$, Buchari Buchari ${ }^{3}$, I Made Arcana $^{4}$ \\ ${ }^{1,2,3}$ Separation and Speciation Analytical Research Groups, Faculty of Mathematic and Natural Sciences, \\ Institut Teknologi Bandung, Ganesha 10, 40132, Bandung-Indonesia \\ ${ }^{4}$ Inorganic and Physical Research Groups, Faculty of Mathematic and Natural Sciences, Institut Teknologi \\ Bandung, Ganesha 10, 40132, Bandung-Indonesia
}

\begin{abstract}
Binary complex of imprint ion in design ion imprinted polymer is significant for solid phase extraction. Various of the imprint degree $(0.001 \mathrm{mmol}, 0.01 \mathrm{mmol}, 0.1$ and $1 \mathrm{mmol})$ have been prepared in polymerization. Ion imprinted polymer were prepared via bulk polymerization methods by forming binary complex Zr-Xylenol orange in 2-methoxy ethanol and copolymerizing in the presence of styrene, divinylbenzene and benzene peroxide as an initiator. Zircon ion were removed from polymer particles by leaching with $\mathrm{HCl}$ to leave the cavity in the polymer particles, filtering, washing, drying in an oven at $50{ }^{\circ} \mathrm{C}$, and grinding. The polymer particles both prior to and after leaching have been characterized by Optical photo and SEM-EDS, IR. The retention capacity of polymers were found to be $4.6 \mathrm{mg}$ zircon ion per gram particle in $\mathrm{pH}$ 6. The decrease of imprint degrees lead to $\mathrm{pH}$ of retention on polymer shift to $\mathrm{pH}$ acidity. It is also influenced on surface and volume pore, and there was no significant effect on retention capacity and pore size. Zircon-imprinted polymer has been applied to zircon ion extraction and optimum on $0.1 \mathrm{mmol}$.
\end{abstract}

Keywords: Imprinted polymers, extraction, SPE, xylenol orange, zirconium

\section{INTRODUCTION}

State of the art in synthesis of material for solid phase extraction is significant to get optimize for extraction process. Ion imprinted polymer is one of methods for synthesis of polymer materials functionalized. They [1-9] crosslinked polystirene by divenylbenzene (DVB) with 5,7-dichloroquinoline-8-ol (DCQ) in presence of metal ion as templates. It is applied to separation preconcentration and determination of ion uranium, palladium, dysprosium, erbium, in their research disclose that the vinylpiridine is able increase the capacity retention. In addition to PSDVB , they have investigated HEMA-EGDMA as backbone polymer. Generally, ion imprinted polymer were synthesized by 2,2'azobisisobutyronitril (AIBN) as initiator in 2methoxy ethanol as porogen. To get more information of ion imprinted polymer can be seen in review article by Prasada Rao et. all.[10]

The xylenol orange (XO) as the chelating agent due to XO is selective chelating agent. Abdul Majeed and Khan M, 1987; Grudpan et al., 1998, they have used XO for selective agent for determination of zirconium by spectrophotometer. Their method has been successful in determination zirconium in NBS steel and eluate from technetium-99m generator samples [11-12].

In this worked, we reported the effect of degree binary complex of ion imprint in synthesis of zirconium imprinted polymer and it were applied for zircon extraction. Zirconium standard commercial is difficult to be got free of hafnium metal caused zirconium and hafnium are associated in nature. They have opposite nuclear characteristics. Thus, they have to be separated prior to their transformation into pure metals. The development of solvent extraction for separated of zirconium and hafnium have been carried out use TBP/NHO3 or MIBK/NaSCN/HNO3. Previous reports have used other solvents for zirconium/hafnium separation (El-yamani and Farrah, 1978; Shults and Larsen, 1950; Kalyanaraman and Khopkar, 1977; Dalsiva et al., 2000; Dalsiva and Distin, 1998; Poriel et al., 2006). Among them the most successful has been used cyanes 925 with extracted $61 \%$ zirconium and $4 \%$ hafnium giving a separation factor 37. Taghizadech et al., have been successful to enrich extraction zirconium up to $71 \%$ at separation factor of 8.1. They have used Taguchi method to investigation the effect of acid type. The experiment has been applied extraction of zirconium in nitric acid solution [13]. This research investigated various mol of binary complex of imprint ion and its applied to zirconium exttacion in aqueous medium in SPE by batch methods.

\section{EXPERIMENTAL}

\subsection{Instrumentation}

ICP-AES (Varian) was used to determination of zircon, $\mathrm{pH}$ meters (Orion) were used for $\mathrm{pH}$ measurements. SEM-EDS (JEOL) was used to scanning surface and morphology of material. Spectroscopy 
infrared (IR-Prestige 21, Shimadzu) was used to obtain spectrum IR of polymer. Surface area and pore size carry out by Quantachrome NovaWin version 11.0 (USA). Optical photo by Cannon microscope optic.

\subsection{Reagents and Materials}

Xylenol orange (XO) tetrasodium and zircon-oxy-chloride were obtained commercially from Merck. Styrene (functional monomers), divinyl benzene (DVB) (crosslinking monomers), 2-methoxyethanol (porogen) and benzene peroxide (BPO) were obtained commercially from Sigma Aldrich. Various binary Zr-XO complex solution with mol ratio $\mathrm{Zr} / \mathrm{XO}: 1 / 1 \mathrm{in} 10 \mathrm{~mL}$ 2-methoxyethanol.

\subsection{Synthesis of ion imprinted polymer (IIP) particle}

2.3.1 Formation of Binary Complex

The binary complex zircon ion with xylenol orange with mol ratio $1 / 1$ was prepared by stirring a mixture of $1 \mathrm{mmol}$ of zircon was prepared by dissolving $\mathrm{ZrOCl} 2.8 \mathrm{H} 2 \mathrm{O}$ with various $0.3222 ; 0.0322 ; 0,0032$ gram and $1 \mathrm{mmol} \mathrm{XO}$ with various $0.7606 ; 0.0761 ; 0.0076$ gram in $10 \mathrm{~mL} 2$-methoxy ethanol .

2.3.2 Copolymerization

A porogen was prepared by stirring mixture of complex Zr-XO $1 \mathrm{mmol}$, styrene $40 \mathrm{mmol}, 40 \mathrm{mmol}$ DVB and BPO $0.61 \mathrm{mmol}$ in $10 \mathrm{~mL}$ 2-methoxyethanol. The polymerization mixture was cooled to $0{ }^{\circ} \mathrm{C}$ and purged with $\mathrm{N}_{2}$ for $10 \mathrm{~min}$, seal and heated at $80{ }^{\circ} \mathrm{C}$ in oil bath with stirring for $4 \mathrm{~h}$. The solid polymer was ground in mortar and dried in $80{ }^{\circ} \mathrm{C}$ for $24 \mathrm{~h}$. The imprint ion zirconium was leached from polymer by stirring with $20 \mathrm{~mL} \mathrm{HCl} 9 \mathrm{M}$ for $24 \mathrm{~h}$, and the excess amount of $\mathrm{HCl}$ was washed with ultra-pure water and then by methanol. After washed, IIP dried in $80{ }^{\circ} \mathrm{C}$ for $24 \mathrm{~h}$. Finally, the particle polymer was dried vacuum in desiccators.

\subsection{Retention capacity}

The retention capacity from aqueous solution was investigated in batch experiment. The particle of polymer $(20 \mathrm{mg}$ ) were suspended in $10 \mathrm{~mL}$ zircon ion $10 \mathrm{mg} / \mathrm{L}$ in aqueous solution and $\mathrm{pH}$ were variated by nitric acid and sodium hydroxide solution. The concentrations of zircon ion in aqueous solution after desired treatment periods were measurement by ICP-AES. Three replicate extraction, and measurements were performed for each aqueous solution. The concentrations of zircon ion prior to and after retentions on particle of polymer.

\subsection{General procedure for zircon extraction}

Zircon-imprinted polymers $(20 \mathrm{mg})$ were added to $10 \mathrm{~mL}$ zircon solution $10 \mathrm{mg} / \mathrm{L}$ after $\mathrm{pH}$ adjusting to 6. Then the mixture was stirred for 24 hours. The zircon ions were eluted from the IIP particle using $10 \mathrm{~mL}$ of $9 \mathrm{M}$ nitric acid. Their content in the eluant were determined by ICP-AES.

\subsection{Optical photo}

\section{RESULT AND DISCUSSION}

The photo optics were shown in fig. 1. From which it is clear occurs different colour significant of particle. Unleached particle colour is purple. This colour from $\mathrm{Zr}$-XO complex and leached particle is red. It is indicates that $\mathrm{Zr}$ have been removed. The decrease of mol complex of imprint ion caused polymer colorless.

\subsection{Scanning electron microscopy (SEM)-Energy disperse spectroscopy (EDS)}

The morphology of polymers produced by bulk polymerization were assessed by SEM-EDS with magnitude 2000 are given in fig. 2. The results show that leached particle morphology is viewed like as a soaked morphology. It is not smooth if compare to unleached particle. Morphology of polymers are leached to unleached is more porous. Polymers are leached by $\mathrm{HCl} 6 \mathrm{M}$ and $\mathrm{HCl} 9 \mathrm{M}$. Zircon ion as ion imprint with complete release from polymer by $\mathrm{HCl} 9 \mathrm{M}$ are given in fig. 3 .

\subsection{IR Spectra}

The IR spectra of unleached and leached zircon imprinted polymer were recorded by using $\mathrm{KBr}$ pellet method. The IR spectra of IIP unleached and leached materials are given in fig. 4. Both IIP have similar IR spectra, which indicates that all the polymers have similar backbone, but they have different intensity spectra. A band near $1080 \mathrm{~cm}^{-1}$ present in unleached material is shifted to higher frequency $1089 \mathrm{~cm}^{-1}$ while leaching.

The shift and decrease in strength of vibration can be attributed to bonding between the zircon with xylenol orange. Generally, these observations indicate that the polymer backbone is same in both unleached and leached IIP particle thus suggesting XO is held onto polymer even after leaching. 


\subsection{BET and BJH Analysis}

Surface and pore size analysis carry out by BET and BJH analysis. The effect of degree binary complex of ion imprint can be presented in table 1 . Surface area and total volume pore optimum on $0.1 \mathrm{mmol}$ complex of ion imprint and polymers are produced there was no influent of various mol complex of ion imprint to pore size.

\subsection{Retention Capacity}

The retention capacity studies by batch methods for $24 \mathrm{~h}$. The result obtained are shown in fig.5. IIP suspended with zircon solution is IIP with $\mathrm{Zr}-\mathrm{XO} 1 / 1 \mathrm{mmol}$ ratio. Maximum retention capacity is $4.6 \mathrm{mg} \mathrm{Zr} / \mathrm{g}$ IIP at $\mathrm{pH}$ 6. In order to investigate the effect of degree binary complex with various is $0.001 ; 0.01 ; 0.1$ and 1 mmol were shown fig.6. There was no effect significant the degree of complex $\mathrm{Zr}$-XO to retention capacity, but it causes shift $\mathrm{pH}$ of retention capacity to $\mathrm{pH}$ acidity when the degree of mmol $\mathrm{Zr}$-XO in IIP particle decreases.

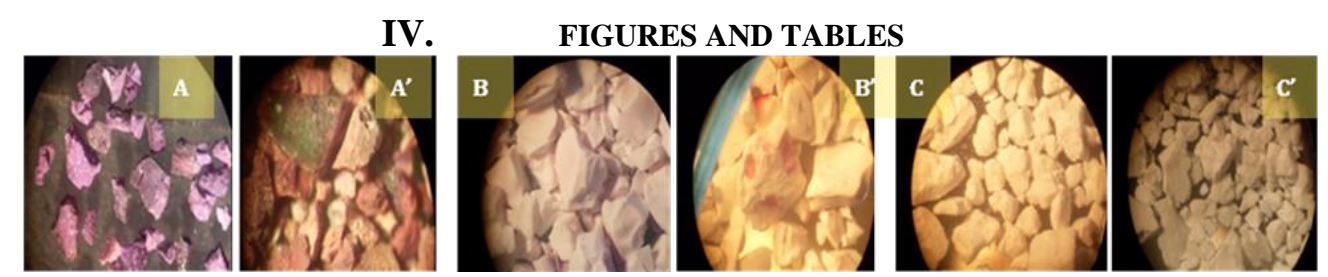

Fig. 1 Photo optic magnitude 600 polymer particle. Unleached

(A:0,1 mmol,B:0,01 mmol,C:0,001 mmol) and leached (A':0,1 mmol, B':0,01 mmol, C':0,001 mmol) polymer.
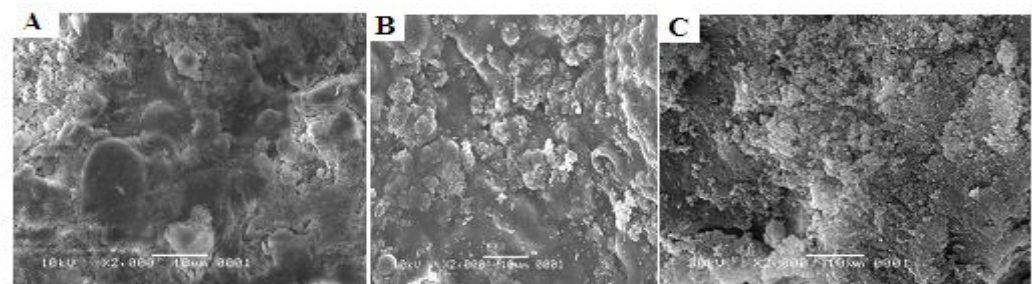

Fig. 2. SEM photograph of IIP : A. leached by $\mathrm{HCl} 6 \mathrm{M}$, B. Leached by $\mathrm{HCl} 9$ M. C.Unleached.
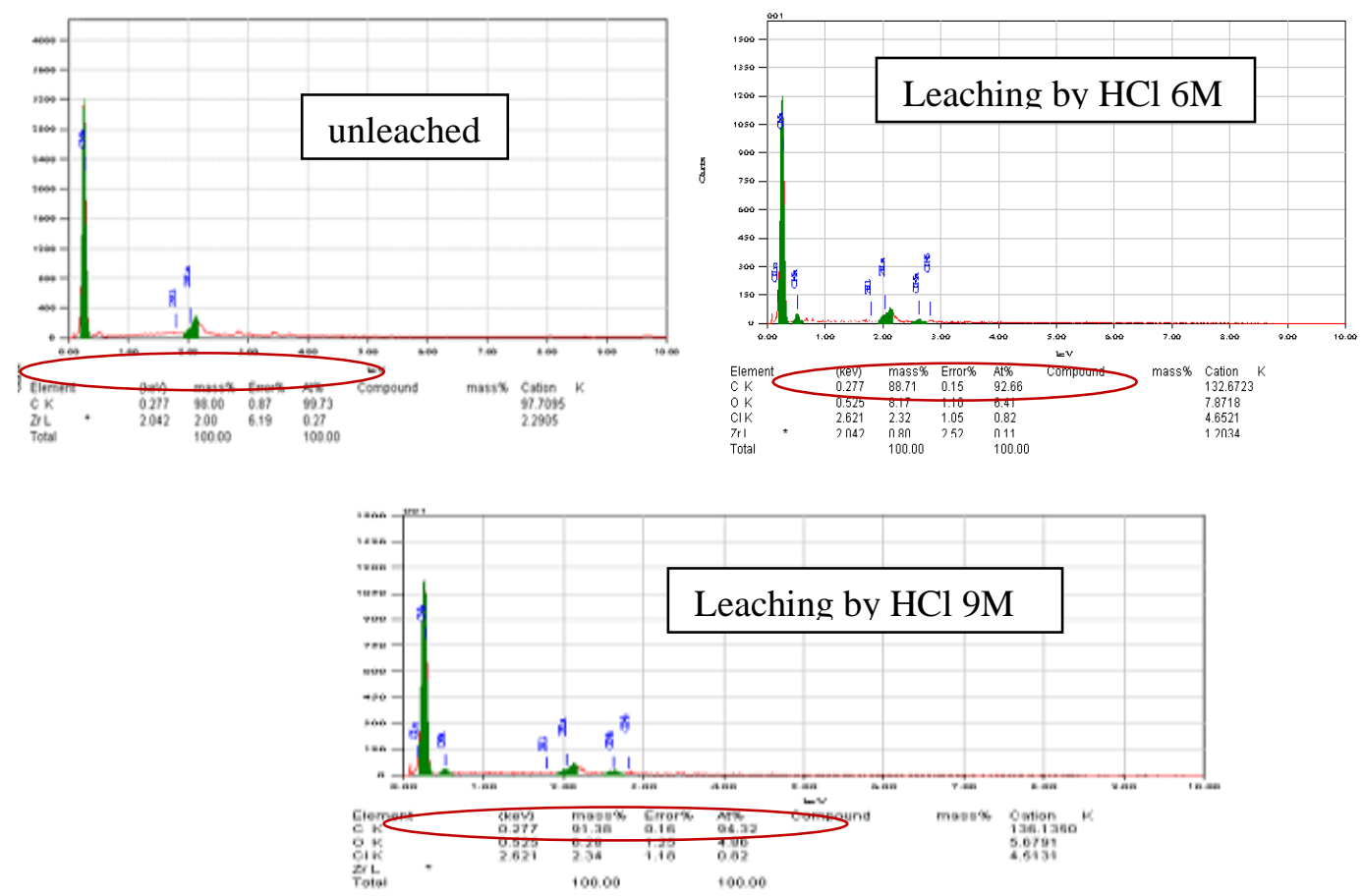

Fig. 3 EDS spectra unleached and leached polymer IIP 


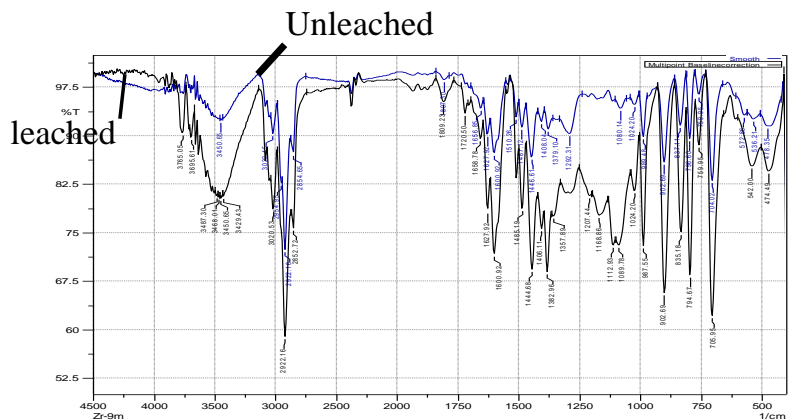

Fig.4 IR spectra of unleached and leached imprinted polymer

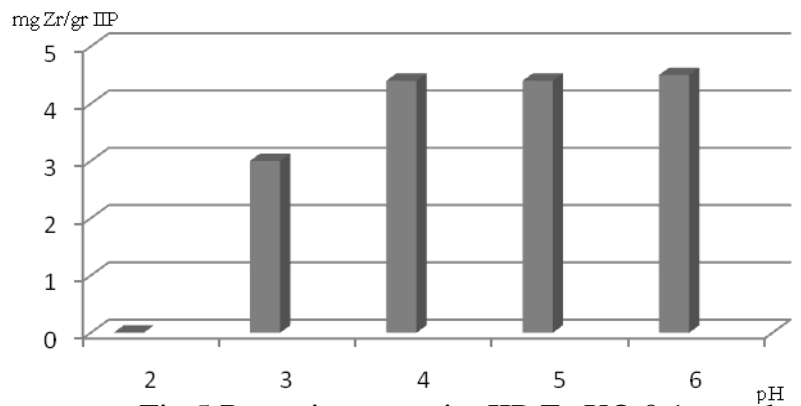

Fig.5 Retention capacity IIP Zr-XO $0.1 \mathrm{mmol}$

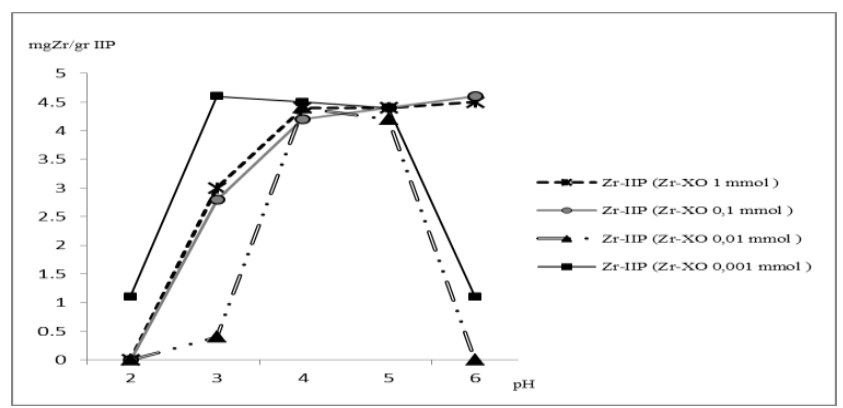

Fig.6 The effect degree complex Zr-XO to retention capacity

Table 1. BET and BJH analysis

\begin{tabular}{|c|c|c|c|c|c|c|c|}
\hline \multirow{4}{*}{$\begin{array}{c}\text { Polyme } \\
\mathbf{r} \\
\text { IIP }\end{array}$} & \multirow{4}{*}{$\begin{array}{c}\text { Degree } \\
\text { Compl } \\
\text { ex } \\
\text { mmol }\end{array}$} & \multicolumn{4}{|c|}{ BET } & \multicolumn{2}{|c|}{ BJH } \\
\hline & & \multicolumn{2}{|c|}{ Single point } & \multicolumn{2}{|c|}{ Multi point } & \multirow{3}{*}{$\begin{array}{c}\begin{array}{c}\text { Total } \\
\text { Volume } \\
\text { pore }\end{array} \\
10^{-3} \\
(\mathrm{cc} / \mathrm{g})\end{array}$} & \multirow{3}{*}{$\begin{array}{c}\begin{array}{c}\text { Average } \\
\text { Radius } \\
\text { pore }\end{array} \\
\mathbf{A}^{\mathbf{o}}\end{array}$} \\
\hline & & $\begin{array}{c}\text { Surface } \\
\text { Area }\end{array}$ & $\begin{array}{c}\text { Specific } \\
\text { Surface } \\
\text { Area }\end{array}$ & $\begin{array}{c}\text { Surface } \\
\text { Area }\end{array}$ & $\begin{array}{c}\text { Specific } \\
\text { Surface } \\
\text { Area }\end{array}$ & & \\
\hline & & $\left(\mathrm{m}^{2}\right)$ & $\left(\mathrm{m}^{2} / \mathrm{g}\right)$ & $\left(\mathrm{m}^{2}\right)$ & $\left(\mathrm{m}^{2} / \mathrm{g}\right)$ & & \\
\hline IIP0.01 & 0.01 & 24.384 & 178.377 & 25.737 & 188.275 & 124.992 & 13.278 \\
\hline IIP0.1 & 0.1 & 31.085 & 262.984 & 32.749 & 277.068 & 182.839 & 13.198 \\
\hline IIP1 & 1 & 2.842 & 33.315 & 3.038 & 35.620 & 23.925 & 13.433 \\
\hline
\end{tabular}

\section{CONCLUSION}

Synthesis ion imprinted polymers is one of functionalized polymers to enhanced extraction. The Degree of mol binary complex of ion imprint can be contributed to produce porous materials polymer. Porous polymers are produced can be used to separate and preconcentrative of zircon ion from hafnium.

\section{Acknowledgements}

The authors gratefully acknowledge research support from to Institute Technology of Bandung and Geology Research Development Centre, Department of Geology-Indonesian Ministry of Energy and Mineral Resources. 


\section{REFERENCES}

[1] Biju V. M, Gladis M. J, Prasadarao T.. Ion imprinted polymer particles: synthesis,characterization and dysprosium ion uptake properties suitable for analytical application. J. Analytical ChimicaActa, 478, 2003, 43-51

[2] Kala R., Gladis M. J, Prasadarao T., Preconcentrative separation of erbium from Y, Dy, Ho, Tb and Tm by using ion imprinted polymer particles via solid phase extraction. J. Analytical ChimicaActa, 518, 2004, 143-150

[3] Kala R., Biju V., M.,PrasadaRao T., Sythesis, characterization and analytical applications of erbium(III) ion imprinted polymer particles prepared via $\gamma$-irradiation with different fuctional and crosslinking monomers. J. Analytical ChimicaActa, 549, 2005, 51-58

[4] Metilda P., Gladis M. J, Prasadarao T., Influence of binary/ternary complex of imprint ion on the preconcentrration of uranium(VI) using ion imprinted polymer materials. J. Analytical ChimicaActa, 512, 2004 63-73

[5] Metilda P., Prasad K., Kala R., Gladis M. J., PrasadaRao T., Naidu G. R. K., Ion imprinted polymer based sensor for monitoring toxic uranium in environmental samples. J. Analytical ChimicaActa, 582, 2007, 147-153

[6] Metilda P., Gladis M. J., Venkateswaran G., PrasadaRao T., Investigation of the role of chelating ligand in the synthesis of ionimprinted polymeric resins on the selective enrichnment of uranium(VI). J. Analytical ChimicaActa, 587, 2007, 263-271

[7] Prasad K., Kala R., PrasadaRao T., Naidu G. R. K., Ion imprinted polymer based ion-selective electrode for the trace determination of dysprosium(III) ions. J. Analytical ChimicaActa, 566, 2006, 69-74

[8] Shobi D., Praveen R. S., Prasadarao T., Ternary ion-association complex based ion imprinted polymers(IIPs) for trace determination of palladium(II) in eviromental samples. J. Analytical ChimicaActa, 570,79-87

[9] Shobi D., PrabhakaraRao P., Prasadarao T., Investigation of different polymerization methods on the analytical performance of palladium(II) ion imprinted polymer materials. J. Analytical ChimicaActa, 536, 2005, 197-206

[10] PrasadaRao T., Kala R., Daniels S., Metal ion-imprinted polymers-Novel materials for selective recognition of inorganics. J. Analytical ChimicaActa,Review, 578, 2006, 105-116

[11] KateGrudpan, Mayuree U., Colin G. T., Determination of zirconium with xylenol orange by flow injection spectrophotometry : application to eluates from technetium-99m generators. Analytical communication, 35, 1998, 107-108

[12] Majeed A., Khan S. M., Spectrophotometric determination of zirconium in steels with xylenol orange. J. Analytical ChimicaActa, Short comication, 192, 1987, 125-128

[13] Taghizadeh M., Ghasemzadeh R., Ashrafizadeh S. N., Saberyan K., GhanadiMaragheh M. Determination of optimum process for the extraction and separation of zirconium and hafnium by solvent extraction. J. Hydrometallurgy, 90, 2008, 115-120 